\title{
THE IMPACT OF HYBRID WORKPLACE MODELS ON INTANGIBLE ASSETS: THE GASE OF AN EMERGING GOUNTRY
}

\author{
Milenko Radonić ${ }^{1}$, Valentina Vukmirović ${ }^{2}$ and Miloš Milosavljević ${ }^{* 3}$ \\ ${ }^{13)}$ University of Belgrade, Belgrade, Serbia \\ ${ }^{2)}$ Institute of Economic Sciences, Belgrade, Serbia
}

Please cite this article as:

Radonić, M., Vukmirović, V. and Milosavljević, M., 2021. The Impact of Hybrid Workplace Models on Intangible Assets: The Case of an Emerging Country. Article History

Received: 30 March 2021

Revised: 8 May 2021

Amfiteatru Economic, 23(58), pp. 770-786.

Accepted: 27 June 201

DOI: $10.24818 / \mathrm{EA} / 2021 / 58 / 770$

\begin{abstract}
As part of a safety-first principle during the COVID-19 pandemics, the vast majority of companies have enabled flexible working environments, reducing the number of employees in the premises. The global best practices have firstly been recorded among the ICT companies which offered teleworking to their employees, empowering safety and flexibility through remote work policies and flexible working hours. Although hybrid working models might become a standard in many industries, only a paucity of papers has examined the relationship between novel working environments and various classes of intangible assets. The aim of this paper is to present the effects of hybrid working models (telework and flexible working hours) on intangible assets (human, relational, structural and intellectual capital). While the existing hybrid work principles have already shown mixed effects on corporate outcomes, its impact on intangible assets remains unrevealed. To address this research gap, we conducted an empirical study. Primary data were collected in the Serbian ICT sector $(\mathrm{N}=122)$ using a structured questionnaire developed for this purpose. Data was analyzed with the OLS regression. The results confirm the positive effects of the hybrid working model on intangible assets of ICT companies, which could further propel the financial success of these companies. In general, these results imply that hybrid working models, which are becoming a standard for many industries, would not jeopardize the creation of intangible assets - the ultimate resource of modern companies.
\end{abstract}

Keywords: hybrid workplace models, flexible working, teleworking, intangible assets, human capital, relational capital, structural capital, intellectual capital

JEL Classification: G32, G41, M54, O34.

* Corresponding author, Miloš Milosavljević - e-mail: milos.milosavljevic @ fon.bg.ac.rs

\section{Authors' ORCID:}

Milenko Radonić: orcid.org/0000-0003-2140-7494

Valentina Vukmirović: orcid.org/0000-0001-8901-5206

Miloš Milosavljević: orcid.org/0000-0002-4965-4676 


\section{Introduction}

From the earliest days of the outbreak of COVID-19, the global economy has shifted and adjusted the workplace models. Accordingly, the WHO has proposed guidelines and offered recommendations for the workplace through the work model transitions (Shaw et al., 2020). The traditional ways of working required physical presence on site and the utilization of workplace as the official place where work is done. With the COVID-19 global pandemic, many companies have challenged the status quo and started reshaping the existing and adopting new business models, through technology improvements and setting up a necessary infrastructure.

Social and spatial distance requirements have become a challenge for traditional workplace models focusing on in-office experience. Employee well-being and safety first have been regulated by law in many economies and have even been set as the corporate goals for many organizations (Liu, 2019). However, nowadays, in the paradigm of the global pandemic, safety first has received another connotation and has become a default principle worldwide.

Technology improvements were one of the basic steps in setting the first pillar of teleworking, later on described as a hybrid working model. Even though such technology already existed, the global pandemic has only empowered companies to start using it sooner and to digitalize the global economy. Video conferencing was one of the first improvements which was adopted not just by corporations, but also by public administration and schools (Teräs et al., 2020). Industry 4.0 has brought new innovations in technology use, making it possible for the manufacturing as well to operate through virtually managed machines (Javaid et al., 2020). Therefore, technology has made the transition from working from the office to remote working possible. Of course, not all of the industries had the equal possibilities and infrastructures to switch to remote working. The ICT industry was the pioneer in the transition from traditional workplace models to flexible environments, making remote work possible for many employees and creating lowrisk work environments. On the other hand, some industries had to stop their operations temporarily (especially travel and tourism). Many companies had to adjust their workplace models, switching from office-based environments to online operations, e-commerce and shared economy models (Elrhim and Elsayed, 2020). On the other hand, workers worldwide have experienced a radical change in work ethics and work habits, adjusting their day-to-day working routine.

Although the ongoing pandemic has brought many challenges to the global economy, it has also provided new opportunities, for both companies and employees. Increased work-life balance, better childcare, reduced time in traffic, as well as the transportation costs are only some of the benefits employees have experienced. Moreover, communities have also found a benefit, through less air pollution during police curfews. Overall, there are some studies which have shown the negative impact of new workplace models on employees, through increased levels of stress and anxiety (Shaw et al., 2020). Other studies, however, find flexible working regime as a positive change for many employees globally (Johannessen, 2018). As a new standard for workplaces globally, many companies have adopted the flexible working environment policy, also mentioned as hybrid or distributed workplace models. 
Ever since the 1970 's, the studies have been presenting and advocating a positive relationship between flexible working hours and employee productivity (Schein, Maurer and Novak, 1977). Lower absenteeism, employee turnover and espionage among employees are considered as only a few of the factors which might be affected by flexible working hours (Stella, 2020). As part of intangible assets, human capital has already started seeing the effects of hybrid working models on its performance. In a recent study by Radonić and Milosavljević (2019), the new human practices have been analyzed as part of intangible assets in public administration. Similarly, sustainability of the human capital in the public administration has been reviewed through the aspects of downsizing and productivity as part of the performance indicators (Čudanov, Jaško and Săvoiu, 2012). Moreover, the other studies have perceived the importance of intangible assets from different angles and have demonstrated the relationship between intangible asset categories in a more corporate environment. More holistic approach, presenting the importance of intangible assets has been reviewed in a study performed by Kaplan and Norton, (2004). It was shown that more than $75 \%$ of the total value of companies is related to intangible assets. Nowadays, during the era of ICT dominancy, this percentage goes even above $90 \%$. A complex structure of intangible assets is one of the key problems in managing it.

Therefore, this study has analyzed not just the hybrid workplace models, but also the structure of intangible assets and the relationship between these variables. Additionally, new workplace models have the impact on both - intangible assets and financial performance indicators. However, intangible assets have become a synonym for the success of adopting new business strategies and new business models. Therefore, the keynote from this study is oriented towards examining the relationship between hybrid workplace models and intangible assets. By following some of the latest studies, hybrid workplace models are mostly perceived as two variables - flexible working hours and remote working options. The hybrid working systems and the future of work might not be a novel study, as the body of knowledge has been steadily growing in the last few decades around this topic (Bercovici and Bercovici, 2019). Likewise, the extent evidence on the importance of intangible assets has been vastly discussed topic lately (i.e. Radonić, Milosavljević and Knežević, 2021). Nonetheless, to the best of our knowledge, none of the concurrent studies has examined the relationships and effect of flexible working system on intangible assets of the company. The aforementioned particularly refers to the geographical context (Serbia), and industry-specific (the ICT sector) momentum of the study.

This study contributed to the concurrent body of knowledge by emphasizing the positive sides of telework in the IT industry. In other industries and sectors, a number of studies from the pandemic period have reported negative sides of hybrid work (Palumbo, 2020). However, the workers in IT industry and knowledge-based professions in general, have a background in teleworking and flexible working hours. These workers might never be eager to go to the office for work. On the other side, some novel studies even report on the 'fear from going back to work' (Bughin and Cincera, 2020). The main contribution of our paper is to examine and explore whether hybrid working regimes positively or negatively affect business performances, in particular - intangible assets.

The remainder of this paper is organized through several main sections. The following section is related to the literature review which emphasizes the hybrid working models and intangible assets as the key success factors. Section 2 puts a highlight on the research methodology including the hypotheses, research instrument, measures and variables and sampling procedure. 
Afterwards, the results of the study are presented in the research section, followed by discussion points and the contextualization of the study findings. The final part of this paper is reserved for the conclusion with the recommendations for future research.

\section{Literature review}

Since the outbreak of the ongoing global pandemic, hybrid workplace models have become widely adopted. Since flexible working is an information technology enabled practice, it allows employees to choose work location as business activities can be performed beyond the confines of traditional offices (Chung and van der Lippe, 2018). Many industries have seen both positive and negative outcomes of teleworking or flexible working hours. Raišienè et al. (2020) infer that telework enables hiring professionals regardless of their geographical location and time zone, making a greater potential for human capital creation. Some authors argue that work intensification is the potential outcome of flexible working practices (Kelliher and Anderson, 2009) and longer working hours which are oftentimes unpaid (Chen and McDonald, 2014). Similarly, flexible work practices are considered somewhat challenging in the sense of employee management (De Menezes and Kelliher, 2016). However, the current body of knowledge have shown many positive aspects as well. Wheatley (2016) argues on the "win-win" outcome of flexible working arrangements, stating that healthier and satisfied employees drive business results through increased performance. Moen et al. (2016) observed the influence of organizational intervention whose aim was to improve employee well-being and psychological health by providing them with greater work time control. Among the observed group of high-tech employees, the authors proved a positive effect of workplace flexibility initiative on the reduction of stress levels and feelings of burnout and the increase in job satisfaction. Anyhow, a growing body of literature points out that teleworking and flexible working hours might remain the preferred working practice even after the COVID-19 pandemic abates (Contreras et al. 2020). On the other hand, the effects of hybrid workplace models on intangible assets segments remained an opened puzzle and unexplored area.

By focusing on intangible assets, the vast majority of research have proven the importance of intangible assets from different perspectives - effects on financial performance, effects on company value and effects on overall success of the company (Radonić, Milosavljević and Knežević, 2021). As for the main segments of intangible assets, our study uses the categorization of Wang and Chang (2005). They narrow down intangibles to four key segments: human, relational, structural and innovation capital. This intangible assets structure will also be used in this study, focusing on the effects of hybrid workplace models on each segment.

\subsection{Hybrid workplace models and human capital}

Flexible working practices provide employees with the opportunity to choose a working arrangement which best suits the requirements of their private and professional lives. Those arrangements make part of human resource strategies which aim to attract and retain skilled professionals, vital for reaching organizational objectives (Peters et al., 2016). Employees can benefit from the flexibility of working hours, such as the reduced or non-standard hours (Kelliher and Anderson, 2009) and compressed working hours (De Menezes and Kelliher, 
2016). Higher job satisfaction in the context of new ways of working is tightly connected to increased productivity as well as organizational commitment (De Leede and Heuver, 2016). Flexible work arrangements were proved to positively influence co-workers' connectivity which resulted in better work performance (Zhang and Viswanath, 2013), higher work engagement and reduction of work fatigue (Brummelhuis et al., 2012). Kniffin et al. (2020) argue that employees who accomplish complex tasks individually, without much interaction with colleagues, feel more comfortable and achieve higher productivity when working from home. Therefore, teleworking can arguably allow for better alignment of employee personality and job demands, which positively influences their attitude towards work and enhances human capital through proper managing (Smith et al., 2018). Accordingly, this study hypothesizes that:

H1: Hybrid workplace models (teleworking and flexible working) positively affect human capital.

\subsection{Hybrid workplace models and relational capital}

Davidescu et al. (2020) examined the influence of work flexibility on human and relational capital among Romanian employees. The authors have proved that partial home working was beneficial professional relationships and the enhancement of organizational performance. Another aspect of relational capital concerns a company's relationship with customers. With the right infrastructure, many companies have continued providing great service, even during the global pandemic and lockdowns. In the paper of Shaheen et al. (2019), it was proved that psychological capital of the employees in the healthcare sector, which is enabled by well-balanced work and personal life due to flexible work arrangements, positively influenced customer advocacy. Accordingly, this study hypothesizes that:

H2: Hybrid workplace models positively affect relational capital.

\subsection{Hybrid workplace models and structural capital}

Structural capital consists mainly of processes and infrastructure. Multifaceted advantages of distributed meetings software, unified communications and cloud-based platforms have changed the concept of traditional workspace, making it less location- and time-dependent (Williams and LaBrie, 2015). Global pandemic has created a need for process restructuring for many companies and industries. Similarly like the global pandemic, hybrid workplace models have created certain requirement for modern workplaces. As per study by Steenkamp and Kashyap (2010), structural capital could be separated as management methodology, processes, distribution agreements, company culture and databases. All of these elements are crucial in order to provide a sustainable business in the era of hybrid workplace models. Accordingly, this study hypothesizes that:

H3: Hybrid workplace models positively affect structural capital. 


\subsection{Hybrid workplace models and innovation capital}

Based on a series of in-depth interviews, Moll and De Leede (2016) have shown that new ways of working enhance innovative work behavior. Teleworking and flexible working hours were found to have a favorable impact on employee focus, creativity and idea development. Another evidence of the positive influence of flexible work arrangements and innovation performance was provided by Preenen et al. (2015). The authors have proved a beneficial impact of internal labor flexibility practices on organizations' innovation performance as they encourage innovative and creative behavior as well as acquiring and sharing knowledge. On the basis of eight case studies conducted in two telecommunication companies in the Netherlands, Coenen and Kok (2014) proved that teleworking positively influenced the performance of new product development projects. Accordingly, this study hypothesizes that:

H4: Hybrid workplace models positively affect innovation capital.

Following the above discussed development of research hypotheses, we illustrated the hypothesized model as given in Figure no. 1.

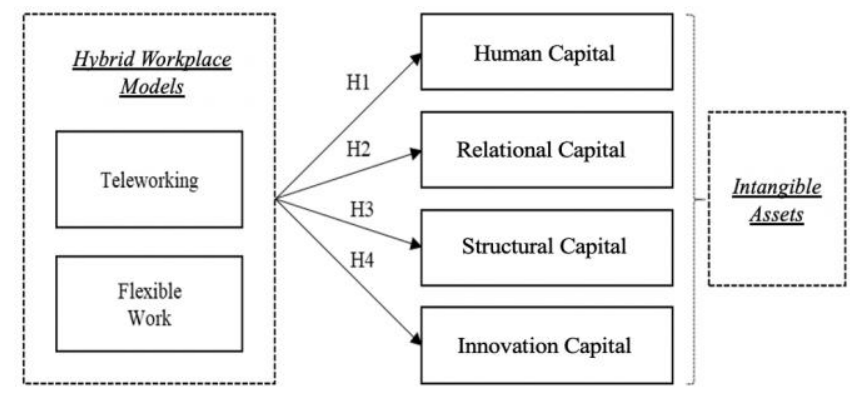

Figure no. 1: Hypothesized model for the hybrid workplace models factors

\section{Research methodology}

\subsection{Research instrument}

To address the aim of the study, we used a questionnaire as a research instrument. More specifically, an e-questionnaire was used to collect responses, thus applying the CAWI technique (Computer Assisted Web Interviewing). During the pandemic, the CAWI technique has been chosen as the most efficient and most secure way of collecting data. The data were collected in February and March of 2021.

\subsection{Questionnaire design}

The questionnaire used for collecting the data in this study had three distinct parts. The first segment of questions was oriented towards collecting the demographic data relating to respondents. The following section of the questionnaire was aimed at collecting the demographic data of the organization the respondents belong to. The third and final section of the questionnaire was focused on collecting the data about hybrid workplace models (independent variables) and their impact on intangible asset components (dependent variables). 
Variables and measures. All the variables were grouped into independent (hybrid working models) and dependent (intangible assets).

Remote working (Telework) and flexible working hours (Flexible Work) have been analyzed as the factors of hybrid workplace models. Many organizations have become united by the challenges imposed by the global pandemic, especially in the most endangered areas and markets. Even though Serbia is not at the top of the 'most hit countries' list, many companies have put effort with the government into establishing a safe and secure environment for their employees, focusing on the two factors - telework (remote working) and flexible working hours.

These two variables were operationalized following the recent study of Baert et al. (2020). More specifically, 11 items were measured within both constructs (telework and flexible working hours): 1) happiness with telework/flexible work, 2) less professional conflicts with telework/flexible work, 3) less disturbances with telework/flexible work, 4) efficiency in combining means of communications, 5) efficient company guidelines for telework/flexible work, 6) a possibility to influence the employer to introduce telework/flexible work, 7) improved task efficiency with better work-life balance with telework/flexible work, 8) better work-life balance with telework/flexible work, 9) lower stress with telework/flexible work, 10) better relationships with colleagues with telework/flexible work, and 11) low burnout and improved work focus with telework/flexible work. For each item, the specific inquiry was 'To what extant do you find the following items being different than in-office/fixed working hours being different...' All the items were measured on a five-point Likert-type scale (1-Completely disagree to 5-Completely agree).

On the other hand, intangible assets have been recognized as one of the key success factors for sustainable competitiveness. A broad body of knowledge has been centered around the measurement of the value and development of intangible assets in a particular company, which has been explained in the introductory section of this paper.

We operationalized these variables using the approach of Steenkamp and Kashyap (2010). These authors use a 22-items construct grouped into: A) Human Capital: 1) Working experience - number of years working, 2) Formal education level, 3) Personal development and investment in employees, 4) Expertise of employees - knowledge and skills, 5) Employee's innovativeness, 6) Employee's satisfaction, 7) Employee's loyalty, and 8) FTE (\# of full-time employees); B) Relational Capital: 9) Customer satisfaction, 10) Loyalty and customer retention, 11) Number of customers (large customer database), 12) Relations with suppliers, 13) Relations with investors, 14) Relations with other stakeholders; C) Structural Capital: 15) Management and goal setting methodology, 16) Processes (clear and transparent processes), 17) Distribution agreements for products and services (affiliates), 18) Company culture, and 19) Databases (structured and organized databases - great back end); and D) Innovation Capital: 20) Product reputation, 21) Copyrights (on intellectual capital), 22) Bug free product. All the items were measured on a five-point Likert-type scale (1-My company is far below average to 5-My company highly exceeds average). 


\subsection{Sampling procedure}

The main aim of this study was to determine the perception of hybrid workplace models in the era of the global pandemic, and the aspects of the hybrid workplace model, aligning them against intangible assets. The focus was on 'key informants' from the growing ICT sector of Serbia. The concept of 'key informant' implies the C-level of management, which was the first restricting clause for the inclusion in the sample. Additional rationale behind the inclusion of only C-level managers in the sample is to generate an indication for the further use of telework and flexible working hours, assuming that they have the control over the working processes in IT companies. Finally, IT companies have relatively 'flat' organizational structures, with a very high distance between $\mathrm{C}$ and other levels of managers. Thus, any inclusion of lower levels of managers might provoke procedural errors. An additional restricting clause for the inclusion in the sample was that the respondent has had previous experience with both remote working (telework) and flexible working hours (flexible work).

Since the total population of C-level managers in the ICT industry is unknown, we based our study on a snowball sampling technique. The referral chain was initiated by sending the questionnaire to four professional associations. The administrative coordinators from these associations distributed further on the questionnaire to their members. In the second wave, the respondents were asked to further distribute the questionnaires to their high ranked colleagues (other $\mathrm{C}$ level managers from their company). All the questionnaires were coded and actively controlled to interdict any possible invasive sub-clustering (Milanović, Milosavljević and Milošević, 2019). This was particularly important for the case of Serbian ICT industry, as a significant proportion of ICT experts work as freelancers. Accordingly, we based the study on a convenience sampling (as in Damnjanovic, Proud, and Milosavljevic, 2020).

\subsection{Responses}

We initially collected 209 responses and excluded all the invalid questionnaires. Three criteria were used, two of which were aforementioned (the respondent is the 'key informant' and the respondent has experience with both telework and flexible working hours). The last exclusion criterion was of a technical nature - all the responses with less than $90 \%$ of correctly fulfilled answers were excluded. Finally, a total of 122 responses were categorized as valid. Having in mind that only the C-level managers working in the ICT companies that have had previous experience in both in-office and telework, and fixed and flexible working hours, the sample size could be marked as sufficient.

The sample was gender balanced $-50.8 \%$ were male, whereas $49.2 \%$ were female respondents. As for the age structure, the mean age was 34.34 years, the youngest respondent was 24 , the oldest was 63 , and the median was 30 years old. Slightly less than $15 \%$ of the respondents were above age 40 , which was somewhat expected for the ICT industry. The educational and working experience breakdown is shown in Table no. 1. 
Table no. 1. Education and Working experience of examinees

\begin{tabular}{lrrrrr}
\hline \multicolumn{1}{c}{ Education } & Frequency & \multicolumn{1}{c}{$\%$} & Working experience & Frequency & \% \\
\hline Secondary & 4 & 3.3 & $<5$ & 20 & 16.4 \\
Professional & 11 & 9.0 & $5-10$ & 56 & 45.9 \\
Ongoing Tertiary & 5 & 4.1 & $11-20$ & 39 & 32.0 \\
Tertiary & 92 & 75.4 & $>20$ & 7 & 5.7 \\
PhD & 10 & 8.2 & & & \\
\hline
\end{tabular}

Finally, as for the company size, the majority of respondents worked in large companies $(54.9 \%)$ followed by medium-sized $(24 \%)$, and small $(18 \%)$. The remainder worked in micro companies or as freelancers.

\section{Results}

Prior to testing the study hypotheses, we conducted a pre-analysis including the descriptive analysis of individual items (means and standard deviations), descriptive analysis of variable constructs (means and standard deviations), reliability analysis (Cronbach's Alpha) for multi-itemed constructs, correlation analysis (Pearson moment two-tailed coefficient analysis) to test interdependence among independent and dependent variables.

The descriptive analysis for the individual items is not included in this manuscript (due to the article length restriction), but is available upon the request sent to authors. As for the multi-itemed constructs (Telework, Flexible Work, Human Capital, Relational Capital, Structural Capital and Innovation Capital), the results are displayed in Table no. 2.

Table no. 2. Descriptive statistics, reliability analysis and the correlation matrix for the observed variables

\begin{tabular}{lcccccccc}
\hline & Mean & STD & $\boldsymbol{\alpha}$ & $\mathbf{2}$ & $\mathbf{3}$ & $\mathbf{4}$ & $\mathbf{5}$ & $\mathbf{6}$ \\
\hline Telework & 3.389 & .682 & .857 & $.610^{* *}$ & $.678^{* *}$ & $.430^{* *}$ & $.336^{* * *}$ & $.370^{* *}$ \\
Flexible Work & 3.476 & .639 & .855 & & $.504^{* *}$ & $.399^{* *}$ & $.656^{* * *}$ & $.677^{* *}$ \\
Human Capital & 3.477 & .688 & .793 & & & $.354^{* *}$ & $.532^{* *}$ & $.399^{* *}$ \\
Relational Capital & 3.213 & .829 & .915 & & & & $.230^{*}$ & $.409^{* *}$ \\
Structural Capital & 3.820 & .695 & .775 & & & & & $.522^{* *}$ \\
Innovation Capital & 3.227 & .888 & .756 & & & & & \\
\hline
\end{tabular}

Note: $(*) \mathrm{p}<0.05 ;(* *) \mathrm{p}<0.00 ; \alpha-$ Cronbach's Alpha

As the results indicate, the respondents perceived flexible working (Mean=3.476, $\mathrm{STD}=.639$ ) as slightly more advantageous than teleworking (Mean=3.389, STD=.682), which is to some extent expected. Considering the dependent variables, the respondents perceived Structural Capital as the most developed in their organizations (Mean=3.820, STD=.775), followed by Human Capital (Mean=3.477, STD=.793).

All the multi-itemed constructs were checked for internal reliability - by calculating Cronbach's Alpha, which is also presented in 
Table no. 2. All the values were above the threshold traditionally used in social sciences of $\alpha>$.700. For some constructs, such as Telework, Flexible Work (independent variables), and Relational Capital (one of the dependent variables), the value was above .850 , indicating very high internal reliability. This finding is expected, as the items within the variable constructs were rewarded from already empirically tested scales and measures. We also found a number of positive correlations among the observed variables. Importantly, the results indicate statistically significant interdependence between both independent variables, and all the dependent variables. Almost all correlation coefficients could be market either as medium to high (Telework to Human Capital, and Flexible Work to Human Capital, Structural Capital and Innovation Capital). However, we found a number of statistically significant correlations both between dependent and among the independent variables. Accordingly, we conducted multi-collinearity diagnostics for the study variables. For this purpose, for every regression model we additionally analyzed the Durbin-Watson test and Variance-Inflation-Factor (VIF). The results will be separately explained for every hypothesis (regression model). After the thoroughly conducted pre-analysis, we tested the hypotheses of the study. For every hypothesis, we set a separate regression model. In particular we used the OLS regression. Model 1 (multivariate regression model for Human Capital as a dependent variable) testing $\mathrm{H} 1$ is presented in Table no 3.

Table no 3. Regression model for the Human Capital prediction

\begin{tabular}{lcccccc}
\hline Dependent var.: & \multicolumn{2}{c}{ Unst.Coeff } & St.Coeff. & & & \\
Human Capital & B & SE & Beta & t & Sig. & VIF \\
\hline (Constant) & .922 & .270 & & 3.408 & .001 & \\
Telework & .596 & .085 & .591 & 7.038 & .000 & 1.593 \\
Flexible Work & .154 & .090 & .143 & 1.706 & .091 & 1.593 \\
\hline & $\mathbf{R}$ & .688 & Adj R $^{\mathbf{2}}$ & .464 & DW & 1.745 \\
& $\mathbf{R}^{\mathbf{2}}$ & .473 & SE & .504 & $\mathbf{F}$ & 53.418 \\
\hline
\end{tabular}

As shown in Table no 3, the Durbin-Watson (DW) test was 1.745 (between the threshold values $(1.5<\mathrm{DW}<2.5)$, indicating the lack of autocorrelation. The Variance Inflation Factor $(\mathrm{VIF}=1.593)$ was below the threshold of 10. After conducting the Analysis of Variance (ANOVA), the result indicated $F$ value of 53.418, and the significance of $p<.00$. Finally, we tested the hypotheses. The development of Human Capital in ICT companies can be predicted with hybrid working models (Telework and Flexible Work). The value for the $\mathrm{R}$ square was .473 indicating $47.3 \%$ of the variability of the dependent variable (Human Capital). Accordingly, H1 was statistically confirmed. After confirming H1, we tested H2 to see how the hybrid working model affects the relational capital. The results are displayed in Table no. 4.

Table no. 4. Regression model for the Relational Capital prediction

\begin{tabular}{lcccccc}
\hline $\begin{array}{l}\text { Dependent var.: } \\
\text { Relational Capital }\end{array}$ & \multicolumn{2}{c}{ Unst.Coeff } & St.Coeff. & & & \\
\hline (Constant) & 1.008 & .398 & & 2.532 & .013 & \\
Telework & .361 & .125 & .297 & 2.895 & .005 & 1.593 \\
Flexible Work & .283 & .133 & .218 & 2.125 & .036 & 1.593 \\
\hline & $\mathbf{R}$ & .463 & Adj R $\mathbf{R}^{\mathbf{2}}$ & .201 & $\mathbf{D W}$ & 1.885 \\
& $\mathbf{R}^{\mathbf{2}}$ & .214 & $\mathbf{S E}$ & .741 & $\mathbf{F}$ & 16.245 \\
\hline
\end{tabular}


As shown in Table no. 4, the Durbin-Watson (DW) test was 1.885 (between the threshold values $(1.5<\mathrm{DW}<2.5)$, indicating the lack of autocorrelation. The Variance Inflation Factor $(\mathrm{VIF}=1.593)$ was below the threshold of 10. After conducting the Analysis of Variance (ANOVA), the result indicated $F$ value of 16.245 , and the significance of $p<.00$. The development of Relational Capital in ICT companies can be predicted with hybrid working models (Telework and Flexible Work). The value for the $\mathrm{R}$ square was .214 indicating $21.4 \%$ of the variability of the dependent variable (Relational Capital). Accordingly, H2 was statistically confirmed.

Following the test for the first two hypotheses, we tested $\mathrm{H} 3$ with the results shown in Table no. 5.

Table no. 5. Regression model for the Structural Capital prediction

\begin{tabular}{lcccccc}
\hline Dependent var.: & \multicolumn{2}{c}{ Unst.Coeff } & St.Coeff. & & & \\
Structural Capital & B & SE & Beta & t & Sig. & VIF \\
\hline (Constant) & 1.457 & .282 & & 5.158 & .000 & \\
Telework & -.104 & .088 & -.102 & -1.180 & .241 & 1.593 \\
Flexible Work & .781 & .094 & .719 & 8.281 & .000 & 1.593 \\
\hline & $\mathbf{R}$ & .661 & Adj R $^{\mathbf{2}}$ & .428 & DW & 1.756 \\
& $\mathbf{R}^{2}$ & .437 & SE & .526 & F & 46.220 \\
\hline
\end{tabular}

As shown in

Table no. 5, the Durbin-Watson (DW) test was 1.756, and the Variance Inflation Factor $(\mathrm{VIF}=1.593)$. The result for the $\mathrm{F}$ value was 16.245 , and the significance of $\mathrm{p}<.00$. Finally, we tested the hypotheses. The OLS for Structural Capital in the sampled companies was ( $2=.437$ ), meaning that $43.7 \%$ of the variability of the dependent variable (Structural Capital) was explained with the hybrid working model. Accordingly, H3 was statistically confirmed. Analogously to the aforementioned analyses, we tested H4. Once again, no auto- or multi-collinearity was detected, and the model was statistically significant $(\mathrm{p}<.00)$. We confirmed H4 with R2=.461. These results are presented in Table no. 6 .

Table no. 6. Regression model for the Innovation Capital prediction

\begin{tabular}{lcccccc}
\hline $\begin{array}{l}\text { Dependent var.: } \\
\text { Innovation Capital }\end{array}$ & $\mathbf{B}$ & Unst.Coeff & St.Coeff. & & & \\
Beta & $\mathbf{t}$ & Sig. & VIF \\
\hline (Constant) & .058 & .353 & & .166 & .869 & \\
Telework & -.088 & .111 & -.068 & -.799 & .426 & 1.593 \\
Flexible Work & .998 & .118 & .718 & 8.463 & .000 & 1.593 \\
\hline & $\mathbf{R}$ & .679 & Adj R $^{\mathbf{2}}$ & .452 & $\mathbf{D W}$ & 1.844 \\
& $\mathbf{R}^{2}$ & .461 & SE & .657 & $\mathbf{F}$ & \\
\hline
\end{tabular}

\section{Discussions}

\subsection{Key findings}

The aim of this study was to examine the influence of hybrid working models (remote working and flexible working hours) on intangible assets (Human, relational, structural, and innovation capital) of ICT companies in Serbia. Accordingly, we set four hypotheses. Based on primary data collected from the specially designed questionnaire to fit the 
aforementioned aim, we collected responses from $122 \mathrm{C}$-level managers from the ICT sector. In a nutshell, we confirmed all four hypotheses, as presented in Figure no. 2.

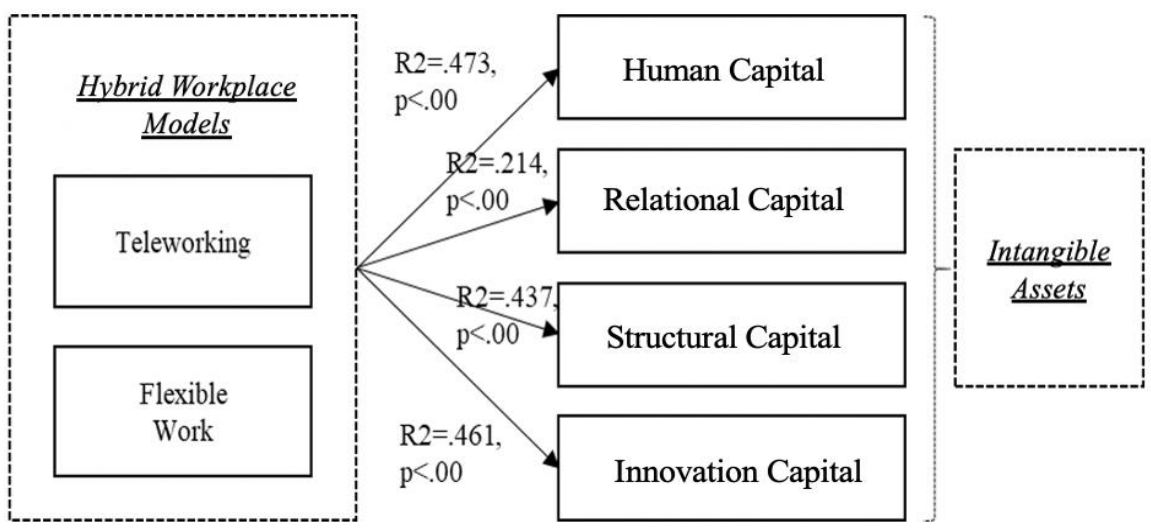

Figure no. 2. Validated models

\subsection{Contributions and implications}

As noted in the literature review section, hybrid working models are not a novel topic. This paper is an attempt to put additional spotlight on the ever-growing knowledge of a changing working landscape (i.e. Evangelakos, 2020). The novelty of this study is reporting of the effects of remote work and flexible working on intangible assets - the resources that have already proven to be the most advantageous accelerator of business growth. A concurrent body of knowledge has raised an interrogative on the overall negative effects of hybrid work on business performances, particularly organizational commitment (Wang, Albert and Sun, 2020) since workers start losing the personal touch. On the other side we are witnessing a number of positive effects of telework and flexible working hours (Stiles and Smart, 2020). In particular, the results of our study showed that hybrid working models have the capacity to 1) additionally propel the development of intangible assets, and 2) ultimately drive better business performance of the ICT sector. The latter one might be considered as a judicious judgment, as it has only indirectly been inspected in the study. Having in mind that IT workers as a sub-class 'knowledge workers' spends more

The second important contribution of the study is related to the geographical context. A scholarly body of knowledge has been fulfilled with the reports and evidence coming from the 'Old Continent' (such as Gálvez, Tirado and Alcaraz, 2019; Raišienè et al., 2020). Nonetheless, this paper is a modest contribution on the effects of the possible future of hybrid working from South-East Europe, and Serbia in particular. This paper is in line with the findings of the studies from the region which usually set a positive tone to hybrid working environments (Vallasek and Mélypataki, 2020).

From a grand scheme of things, this paper contributes to the new stream of research that advocates the 'fear of going back to work' (Bughin and Cincera, 2020). The reason why these findings contribute to this novel stream of research is pretty much self-explanatory instead of being reserved for high-end, Silicon-Valley-like professions, work-from-home is now a standard for a myriad of industries. Given that our results imply that hybrid working 
environments drive intangible assets, in-premises work might become obsolete in the near future, at least for the purpose of intangible asset growth.

Implications. The practical implication of these study results could be used by decision makers in managing the hybrid workplace models, especially in reshaping the postCOVID-19 environments and future concepts of employee experience. As for the IT sector, telework and flexible working hours have been vastly used even prior to the pandemic (Milasi, González-Vázquez and Fernández-Macías, 2021). The influence of this work environment paradigm shifts on intangible assets will attract more attention. With the enforced work from home during the pandemics, the findings of our study might even spill over to other knowledge intensive sectors.

Hybrid working environments might effectively improve intangible assets and accordingly drive business growth, an office might ultimately become a residual of history rather a standard for work. Although these claims are highly speculative, they simply mean that change and improvements are an imperative for any organization, let alone the disruptive industries such as IT. The investment in plausible physical offices has to be altered with the investment in the attractive platform-based work environments. Also, new equilibriums will be required for the optimal work-life-balance needed to boost organizational commitment. These investments in human and structural capital will allow for further extension to relational and intellectual capital, and finally create competitive advantage of such entities, as inferred by Kumukama (2013).

More precisely, this study emphasizes the importance of flexible work options and telework through measuring its impact on four key segments of intangible assets. Accordingly, hybrid workplace models could be taken into account in determining the effects of intangible asset segments on the financial performance of companies.

\section{Conclusions}

This study provides an overview of modern workplace models, with a special accent on flexible working hours and teleworking as parts of hybrid or distributed working concepts. These concepts have received particular attention with the ongoing global pandemic. On the other hand, many studies have advocated the importance of intangible assets as key success factors for many economies. Therefore, the analysis and results provided in this study have shown the importance of measuring the influence of hybrid workplace models on the main components of intangible assets. As it is hard to separately analyse the impact on each intangible asset (22), the authors have grouped them into four main segments. The first results indicated that hybrid workplace models affect the intangible assets. More specifically, human, innovation and structural capital have the highest rate of variability.

Our paper contributes to both theory and practice. From the theoretical point of view, workplace environments have only rarely been directly linked to all the classes of intangible assets. We have shown that hybrid working environments positively affect and empower not only human capital, but also structural, relational and intellectual capital. From the practical point of view, even though the basic concepts of what the future of work might look like is already known, the global pandemic or any similar crisis might affect the ways businesses perceive work and where work is done. In a nutshell, hybrid workplace models do offer more flexibility and balanced work-life for employees, while the need for 
collaboration space will not stop to exist. On the other hand, 'Silicon Valley' culture and big capital investment into real estate and offices might stop being the key factors for defining workplace excellence and attracting talent.

Our study has a number of flaws, which are at the same time the avenues for further research. Being quantitative and cross-sectional by nature, it is exposed to a number of limitations. First, we only captured a portion of variability which means that there is an avenue for further research in additional features of both independent and dependent variables. Second, the study is geographically constrained as the results come from Serbia. Although the ICT industry is heavily globalized, generalization to other markets might bring about a myriad of judicious judgements. Finally, the study is cross-sectional. Having in mind that it inspects the effects of changing workspace realm, follow-up studies might include the time as an inevitable dimension in all the examined variables. Finally, and the most importantly, this study is based on a relatively small sample. Being exclusive to the responses of the C-level management in the ICT industry, might jeopardize the generalizability of the study findings and the results should be cautiously used in advocating for the future changes in the working regime changes. Additional studies should extend beyond this niche and explore the effects in other industries and among other managerial levels.

\section{References}

Baert, S., Lippens, L., Moens, E., Weytjens, J. and Sterkens, P., 2020. The COVID-19 crisis and telework: A research survey on experiences, expectations and hopes. IZA Discussion Papers, No. 13229. Bonn: Institute of Labor Economics (IZA).

Brummelhuis, L.L., Bakker, A.B., Hetland, J. and Keulemans, L., 2012. Do new ways of working foster work engagement?. Psicothema, 24(1), pp.113-120.

Bughin, J. and Cincera, M., 2020. FOG and Teleworking: Some Labor Economics of Covid-19 (No. 2020-21). ULB-Universite Libre de Bruxelles.

Chen, W. and McDonald, S., 2014. Do networked workers have more control? The implications of teamwork, telework, ICTs, and social capital for job decision latitude. American Behavioral Scientist, [e-journal] 59(4), pp.492-507. doi:10.1177/0002764214556808.

Chung, H. and van der Lippe, T., 2018. Flexible Working, work-life balance, and gender equality: Introduction. Social Indicators Research, [e-journal] 151(2), pp.365-381. doi:10.1007/s11205-018-2025-x.

Coenen, M. and Kok, R. A. W., 2014. Workplace flexibility and new product development performance: The role of telework and flexible work schedules. European Management Journal, [e-journal] 32(4), pp.564-576. doi:10.1016/j.emj.2013.12.003.

Contreras, F., Baykal, E. and Abid, G., 2020. E-leadership and teleworking in times of COVID-19 and beyond: What we know and where do we go. Frontiers in Psychology, [e-journal] 11, 590271. doi:10.3389/fpsyg.2020.590271.

Čudanov, M., Jaško, O. and Săvoiu, G., 2012. Public and public utility enterprises restructuring: Statistical and quantitative aid for ensuring human resource sustainability. Amfiteatru Economic, 14(32), pp.307-322.

Davidescu, A.A., Apostu, S.A., Paul, A. and Casuneanu, I., 2020. Work flexibility, job satisfaction, and job performance among Romanian Employees - Implications for 
sustainable human resource management. Sustainability, [e-journal] 12(15), p.6086. doi:10.3390/su12156086.

Damnjanovic, V., Proud, W. and Milosavljevic, M., 2020. Mentoring development at student international business case competitions. EuroMed Journal of Business, [e-journal] 16(2), pp.154-170. doi:10.1108/emjb-12-2018-0092.

De Leede, J. and Heuver, P., 2016. New ways of working and leadership: An empirical study in the service industry. Advanced Series in Management. S.l: Emerald Group Publishing Ltd. doi: 10.1108/S1877-636120160000016004.

De Menezes, L. M. and Kelliher, C., 2017. Flexible working, individual performance, and employee attitudes: Comparing formal and informal arrangements. Human Resource Management, [e-journal] 56(6), pp.1051-1070. doi:10.1002/hrm.21822.

Elrhim, M. A. and Elsayed, A., 2020. The Effect of COVID-19 Spread on the e-commerce market: The case of the 5 largest e-commerce companies in the world. SSRN Electronic Journal, [e-journal]. doi:10.2139/ssrn.3621166.

Evangelakos, G., 2020. Keeping critical assets safe when teleworking is the new norm. Network Security, [e-journal] 2020(6), pp.11-14. doi:10.1016/s1353-4858(20)30067-2.

Gálvez, A., Tirado, F. and Alcaraz, J.M., 2019. "Oh! Teleworking!" Regimes of engagement and the lived experience of female Spanish teleworkers. Business Ethics: A European Review, [e-journal] 29(1), pp.180-192. doi:10.1111/beer.12240.

Javaid, M., Haleem, A., Vaishya, R., Bahl, S., Suman, R. and Vaish, A., 2020. Industry 4.0 technologies and their applications in fighting COVID-19 pandemic. Diabetes and Metabolic Syndrome: Clinical Research and Reviews, [e-journal] 14(4), pp.419-422. doi:10.1016/j.dsx.2020.04.032.

Johannessen, J. A., 2018. The workplace of the future: The Fourth Industrial Revolution, the Precariat and the Death of Hierarchies. S.I: Taylor and Francis. doi:10.4324/9780429441219.

Kaplan, R. S. and Norton, D. P., 2004. Strategy maps: Converting intangible assets into tangible outcomes. S.l: Harvard Business School Press.

Kelliher, C. and Anderson, D., 2009. Doing more with less? Flexible working practices and the intensification of work. Human Relations, [e-journal] 63(1), pp.83-106. doi: $10.1177 / 0018726709349199$.

Kniffin, K. M., 2020. COVID-19 and the Workplace: Implications, issues, and insights for future research and action. American Psychologist, [e-journal] 76(1), pp.63-77. doi:10.1037/amp0000716.

Kamukama, N., 2013. Intellectual capital: company's invisible source of competitive advantage. Competitiveness Review: An International Business Journal, [e-journal] 23(3), pp.260-283. doi:10.1108/10595421311319834

Liu, K., 2019. Regulating health and safety at the workplace: Prescriptive approach vs goaloriented approach. Safety Science, [e-journal] 120, pp.950-961. doi:10.1016/j.ssci.2019.08.034.

Milasi, S., González-Vázquez, I. and E. Fernández-Macías, 2021. Telework before the COVID-19 pandemic: Trends and drivers of differences across the EU. OECD Productivity Working Papers, No. 21. Paris: OECD Publishing. doi:10.1787/d5e42dd1-en. 
Milanović, N., Milosavljević, M. and Milošević, N., 2019. Failure Management Approaches and Public Service Quality: Empirical Evidence from Serbia. Lex localis Journal of Local Self-Government, [e-journal] 17(3), pp.417-434. doi:10.4335/17.3.417433(2019).

Moen, P., Kelly, E.L., Fan, W., Lee, S.R., Almeida, D., Kossek, E.E. and Buxton, O.M., 2016. Does a flexibility/support organizational initiative improve high-tech employees' well-being? Evidence from the work, family, and health network. American Sociological Review, [e-journal] 81(1), pp.134-164. doi:10.1177/0003122415622391.

Moll, F. and De Leede, J., 2016. Fostering innovation: The influence of new ways of working on innovative work behavior. Advanced Series in Management. S.1: Emerald Group Publishing Ltd. doi: 10.1108/S1877-636120160000016006.

Palumbo, R., 2020. Let me go to the office! An investigation into the side effects of working from home on work-life balance. International Journal of Public Sector Management, [e-journal] 33(6/7), pp.771-790. doi:10.1108/ijpsm-06-2020-0150.

Peters, P., Ligthart, P.E., Bardoel, A. and Poutsma, E., 2016. 'Fit'for telework'? Crosscultural variance and task-control explanations in organizations' formal telework practices. The International Journal of Human Resource Management, [e-journal] 27(21), pp.2582-2603. doi: 10.1080/09585192.2016.1232294.

Pierce, J. L. and Newstrom, J. W., 1980. Toward A conceptual clarification of employee responses to flexible working hours: A work adjustment approach. Journal of Management, [e-journal] 6(2), pp.117-134. doi: 10.1177/014920638000600202.

Preenen, P.T., Vergeer, R., Kraan, K. and Dhondt, S., 2017. Labour productivity and innovation performance: The importance of internal labour flexibility practices. Economic and Industrial Democracy, [e-journal] 38(2), pp.271-293. doi: 10.1177/0143831X15572836.

Radonić, M. and Milosavljević, M., 2019. Human resource practices, failure management approaches and innovations in Serbian public administration. Transylvanian Review of Administrative Sciences, [e-journal] 15(Special Issue), pp.77-93. doi: 10.24193/tras.SI2019.5.

Radonić, M., Milosavljević, M. and Knežević, S., 2021 (in press). Intangible assets as financial performance drivers of IT industry: Evidence from an emerging market. Ekonomie a Management, 24(2). Pre-print [online] Available at: $<$ https://www.researchgate.net/profile/Milenko-Radonic-

2/publication/346107378_Intangible_assets_as_financial_performance_drivers_of_IT_i ndustry_Evidence_from_an_emerging_market/links/5ff6dfeba6fdccdcb837d913/Intangi ble-assets-as-financial-performance-drivers-of-IT-industry-Evidence-from-anemerging-market.pdf $>$ [Accessed 27 June 2021].

Raišienè, A. G., Rapuano, V., Varkulevičiūte, K. and Stachová, K., 2020. Working from home-Who is happy? A survey of Lithuania's employees during the COVID-19 quarantine period. Sustainability, [e-journal] 12(13), 5332. doi:10.3390/su12135332.

Saunders, C., Rutkowski, A.F., Genuchten van, M., Vogel, D. and Orrego, J.M., 2011. Virtual space and place: Theory and test. MIS Quarterly, [e-journal] 35, pp.1079-1098. doi: $10.2307 / 41409974$. 
Schein, V. E., Maurer, E. H. and Novak, J. F., 1977. Impact of flexible working hours on productivity. Journal of Applied Psychology, [e-journal] 62(4), pp.463-465. https://doi.org/10.1037/0021-9010.62.4.463

Shaheen, M., Zeba, F., Sekhar, V. and Krishnankutty, R., 2019. Linking home-work interface, work engagement and psychological capital to customer advocacy. Journal of Global Operations and Strategic Sourcing, [e-journal] 12(2), pp.268-287. doi: 10.1108/JGOSS-08-2017-0033.

Shaw, W.S., Main, C.J., Findley, P.A., Collie, A., Kristman, V.L. and Gross, D.P., 2020. Opening the workplace after COVID-19: what lessons can be learned from return-towork research?. Journal of Occupational Rehabilitation. Springer, [e-journal] 30, pp.299-302. doi: 10.1007/s10926-020-09908-9.

Smith, S. A. and Patmos, A. and Pitts, M. J., 2018. Communication and teleworking: A study of communication channel satisfaction, personality, and job satisfaction for teleworking employees. International Journal of Business Communication, [e-journal] 55(1), pp.44-68. doi: 10.1177/2329488415589101.

Steenkamp, N. and Kashyap, V., 2010. Importance and contribution of intangible assets: SME managers' perceptions. Journal of Intellectual Capital, [e-journal] 11(3), pp.368-390. doi: 10.1108/14691931011064590.

Stella, I., 2020. Flexible working arrangements and organizational performance: An overview. IOSR Journal of Humanities and Social Science, [e-journal] 25(6), p.50. Doi: 10.9790/0837-2505065059.

Stiles, J. and Smart, M.J., 2020. Working at home and elsewhere: daily work location, telework, and travel among United States knowledge workers. Transportation. [e-journal]. doi:10.1007/s11116-020-10136-6.

Teräs, M., Suoranta, J., Teräs, H. and Curcher, M., 2020. Post-COVID-19 Education and education technology "solutionism": A seller's market. Postdigital Science and Education, [e-journal] 2(3), pp.863-878. doi: 10.1007/s42438-020-00164-x.

Vallasek, M. and Mélypataki, G., 2020. Rules on home office work and telework in Romania and in Hungary. Central European Journal of Comparative Law, [e-journal] 1(2), pp.177-191. doi:10.47078/2020.2.177-191.

Wang, W., Albert, L. and Sun, Q., 2020. Employee isolation and telecommuter organizational commitment. Employee Relations: The International Journal, [e-journal] 42(3), pp.609-625. doi:1108/er-06-2019-0246.

Williams, J. and LaBrie, R.C., 2015. Unified communications as an enabler of workplace redesign. Measuring Business Excellence, [e-journal] 19(1), pp.81-91. doi:10.1108/MBE-11-2014-0044.

Wheatley, D., 2016. Employee satisfaction and use of flexible working arrangements. Work, Employment and Society, [e-journal] 31(4), pp.567-585. doi: 10.1177/ 0950017016631447.

Zhang, X. and Venkatesh V., 2013. Explaining employee job performance: The role of online and offline workplace communication networks. MIS Quarterly, [e-journal] 37(3), pp.695-722. doi:10.25300/misq/2013/37.3.02. 